OPEN ACCESS

Edited and reviewed by:

Matthias Peichl,

Swedish University of Agricultural

Sciences, Sweden

*Correspondence:

Qiuan Zhu

zhuq@hhu.edu.cn

Pengxiang Zhao

zhaopengxiang@nwafu.edu.cn

Specialty section:

This article was submitted to

Hydrosphere,

a section of the journal

Frontiers in Earth Science

Received: 15 January 2021

Accepted: 03 March 2021

Published: 26 March 2021

Citation:

Zhang J, Zhu Q, Yuan M, Liu X,

Chen $H$, Peng $C$, Wang $M$, Yang $Z$,

Jiang $L$ and Zhao $P$ (2021)

Corrigendum: Extrapolation and

Uncertainty Evaluation of Carbon

Dioxide and Methane Emissions in the

Qinghai-Tibetan Plateau Wetlands

Since the 1960s.

Front. Earth Sci. 9:653753.

doi: 10.3389/feart.2021.653753

\section{Corrigendum: Extrapolation and Uncertainty Evaluation of Carbon Dioxide and Methane Emissions in the Qinghai-Tibetan Plateau Wetlands Since the 1960s}

\begin{abstract}
Jiang Zhang ${ }^{1}$, Qiuan Zhu ${ }^{1,2,3 *}$, Minshu Yuan ${ }^{1}$, Xinwei Liu ${ }^{4}$, Huai Chen ${ }^{4}$, Changhui Peng ${ }^{1,5}$, Meng Wang ${ }^{6}$, Zhenan Yang ${ }^{7}$, Lin Jiang ${ }^{1}$ and Pengxiang Zhao ${ }^{8 *}$

${ }^{1}$ Center for Ecological Forecasting and Global Change, College of Forestry, Northwest A\&F University, Yangling, China, ${ }^{2}$ College of Hydrology and Water Resources, Hohai University, Nanjing, China, ${ }^{3}$ National Earth System Science Data Center, National Science \& Technology Infrastructure of China, Beijing, China, ${ }^{4}$ Chengdu Institute of Biology, Chinese Academy of Sciences, Chengdu, China, ${ }^{5}$ Department of Biology Sciences, Institute of Environment Sciences, University of Quebec at Montreal, Montreal, QC, Canada, ${ }^{6}$ Key Laboratory of Geographical Processes and Ecological Security in Changbai Mountains, Ministry of Education, School of Geographical Sciences, Northeast Normal University, Changchun, China, ${ }^{7}$ Key Laboratory of Southwest China Wildlife Resources Conservation (China West Normal University), Ministry of Education, Nanchong, China, ${ }^{8}$ College of Forestry, Northwest A\&F University, Yangling, China
\end{abstract}

Keywords: climate change, wetlands, greenhouse gas, carbon fluxes, global warming potential

\section{A Corrigendum on}

Extrapolation and Uncertainty Evaluation of Carbon Dioxide and Methane Emissions in the Qinghai-Tibetan Plateau Wetlands Since the 1960s

by Zhang, J., Zhu, Q., Yuan, M., Liu, X., Chen, H., Peng, C., et al. (2020). Front. Earth Sci. 8:361. doi: $10.3389 /$ feart.2020.00361

In the original article, we intended to show the annual mean GHG flux rate within Figures 4, 5, and Table 1. However, there was an oversight in dividing the number by 12 (months).

Below, you can find the corrected Figures 4, 5, and Table 1, as well as the corrections of the numbers cited at various points in the text. The updated section in the Abstract, Page 1, Lines 1114, can be found below. In addition, the updated portion in the Results, section 'Extrapolation of $\mathrm{CO}_{2}$ and $\mathrm{CH}_{4}$ Emission Rates of the Study Site', Page 7, Lines 1-22, can also be found below.

We apologize for these errors and state that this does not change the scientific conclusions of the article in any way. The original article has been updated.

\section{ABSTRACT}

Based on such relationship patterns and soil temperature data (1960-2017), we extrapolated the $\mathrm{CO}_{2}$ and $\mathrm{CH}_{4}$ emissions of study site for the past 57 years: the mean $\mathrm{CO}_{2}$ emission rate was $91.38 \mathrm{mg} \mathrm{C} \mathrm{m}^{-2} \mathrm{~h}^{-1}$ on different measurement methods and timescales, with the range of the mean emission rate from 35.10 to $146.25 \mathrm{mg} \mathrm{C} \mathrm{m}^{-2} \mathrm{~h}^{-1}$, while the mean $\mathrm{CH}_{4}$ emission rate was $2.75 \mathrm{mg} \mathrm{C} \mathrm{m}^{-2} \mathrm{~h}^{-1}$, with the ranges of the mean emission rate from 1.41 to $3.85 \mathrm{mg} \mathrm{C} \mathrm{m}^{-2} \mathrm{~h}^{-1}$. 


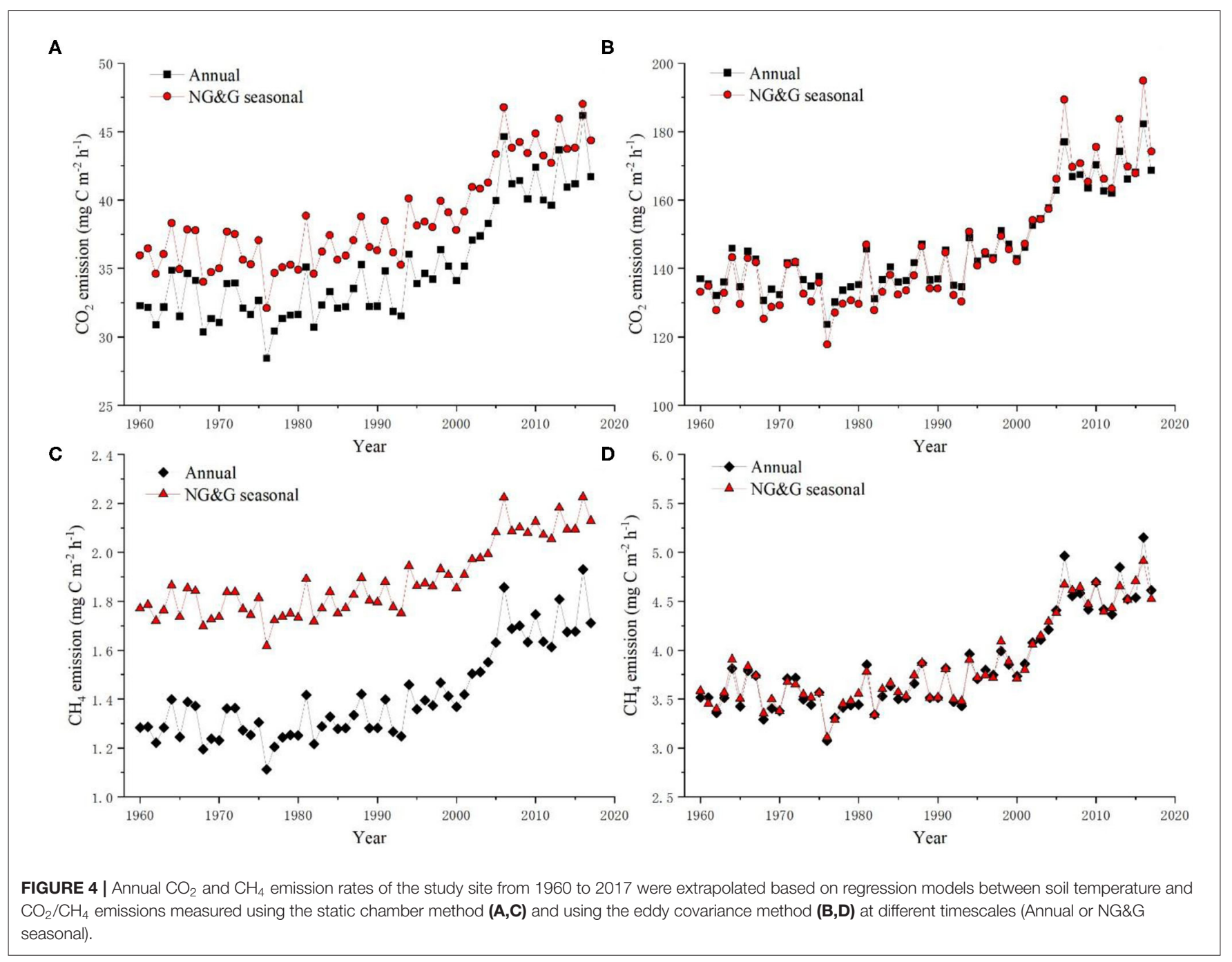




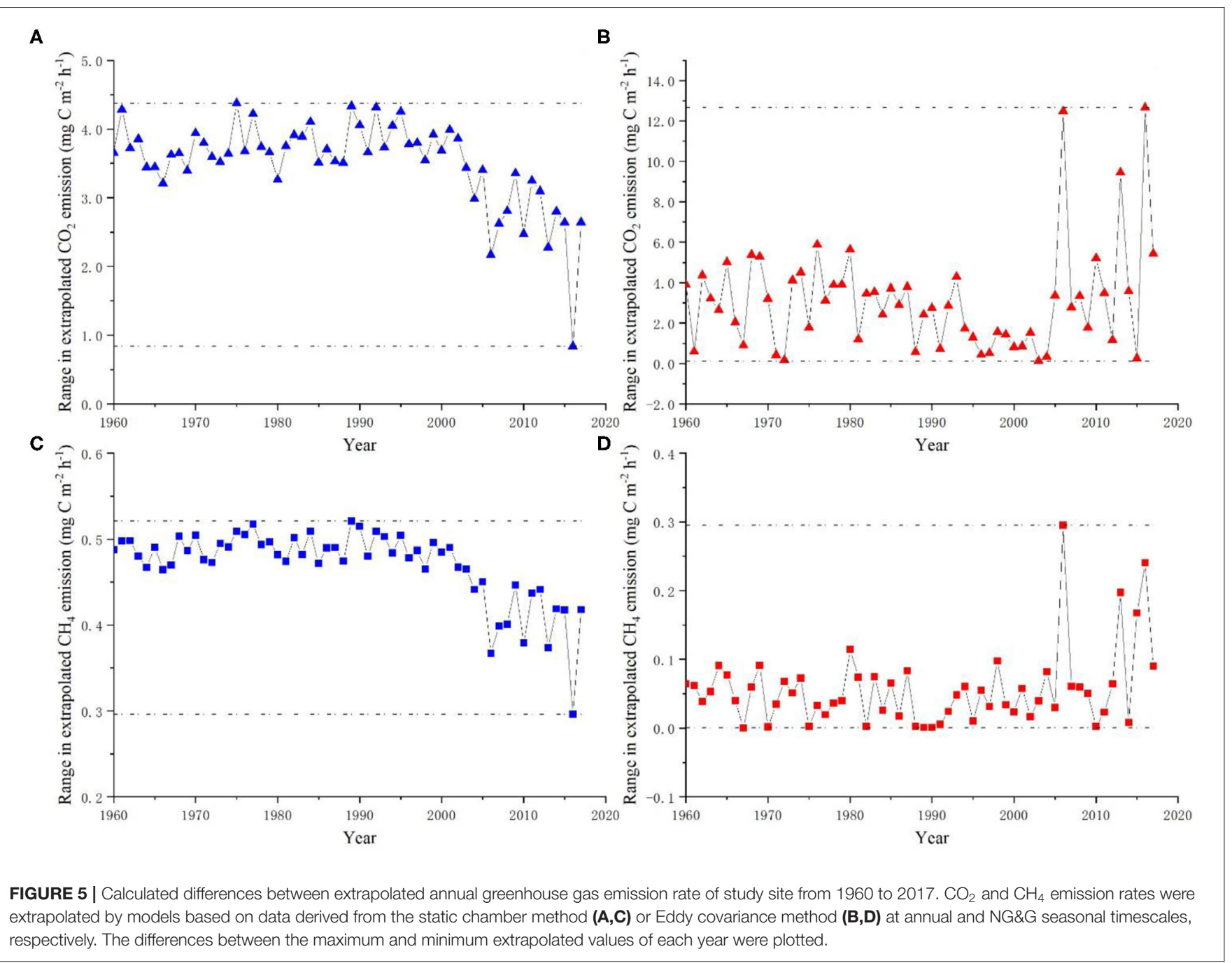

TABLE 1 | Extrapolated mean emission rate of $\mathrm{CO}_{2}$ and $\mathrm{CH}_{4}$ of study site for the period 1960-2017, based on models derived from data obtained using the chamber or EC method at different timescales*.

\begin{tabular}{llcc}
\hline Emission rate $\left(\mathbf{m g ~ C ~} \mathbf{~ m}^{\mathbf{2}} \mathbf{h}^{-1}\right)$ & Measurement method & Annual & NG\&G seasonal \\
\hline $\mathrm{CO}_{2}$ & Chamber & 35.10 & 38.60 \\
& EC & 146.25 & 145.58 \\
$\mathrm{CH}_{4}$ & Chamber & 1.41 & 1.88 \\
& EC & 3.85 & 3.85
\end{tabular}

*Timescales were the entire year (Annual), non-growing season and growing season (NG\&G seasonal). Abbreviations: Chamber, static chamber; EC, eddy covariance.

\section{RESULTS}

\section{Extrapolation of $\mathrm{CO}_{2}$ and $\mathrm{CH}_{4}$ Emission Rates of the Study Site}

Extrapolated mean $\mathrm{CO}_{2}$ emission rate of study site from 1960 to 2017 was calculated to be $91.38 \mathrm{mg} \mathrm{C} \mathrm{m}^{-2} \mathrm{~h}^{-1}$, with the ranges of the mean emission rate from 35.10 to $146.25 \mathrm{mg} \mathrm{C} \mathrm{m}^{-2} \mathrm{~h}^{-1}$ on different measurement methods and timescales (Table 1). The differences of emission rates between the maximum and minimum values extrapolated for each year reflected uncertainties from the same measurement method at different timescales. Uncertainties in extrapolation of the $\mathrm{CO}_{2}$ emission rates ranged from 0.84 to $4.38 \mathrm{mg} \mathrm{C} \mathrm{m}^{-2} \mathrm{~h}^{-1}$ based on static chamber data, and from 0.13 to $12.67 \mathrm{mg} \mathrm{C} \mathrm{m}^{-2} \mathrm{~h}^{-1}$ based on EC data (Figures 5A,B).

Extrapolated values for $\mathrm{CH}_{4}$ emission rate based on EC data were three times larger than extrapolated values based on chamber data (Figures 4C,D). Extrapolated mean $\mathrm{CH}_{4}$ emission rate of the study site was $2.75 \mathrm{mg} \mathrm{C} \mathrm{m}^{-2} \mathrm{~h}^{-1}$ from 1960 to 2017 , with the ranges of the mean emission rate from 1.41 to $3.85 \mathrm{mg}$ 
$\mathrm{C} \mathrm{m}^{-2} \mathrm{~h}^{-1}$ on different measurement methods and timescales (Table 1). Differences in annual average maxima and minima reflected uncertainties from static chamber method data ranging from 0.30 to $0.52 \mathrm{mg} \mathrm{C} \mathrm{m}^{-2} \mathrm{~h}^{-1}$ (Figure $5 \mathrm{C}$ ), while uncertainties in data extrapolated from the EC method ranged from 0 to $0.30 \mathrm{mg} \mathrm{C} \mathrm{m}^{-2} \mathrm{~h}^{-1}$ (Figure 5D).
Copyright $\odot 2021$ Zhang, Zhu, Yuan, Liu, Chen, Peng, Wang, Yang, Jiang and Zhao. This is an open-access article distributed under the terms of the Creative Commons Attribution License (CC BY). The use, distribution or reproduction in other forums is permitted, provided the original author $(s)$ and the copyright owner(s) are credited and that the original publication in this journal is cited, in accordance with accepted academic practice. No use, distribution or reproduction is permitted which does not comply with these terms. 